Clementina Palomo

Beltrán

Doctora, Docente Escuela Superior de Ingeniería y Arquitectura (ESIA), Unidad Tecamachalco - Facultad de Arquitectura de La Salle Trabajadora independiente - Instituto Politécnico Nacional (IPN) Ciudad de México, México https://orcid.org/0000-0002-9410-4227 palomo.clementina@gmail.com

Aleyda Reséndiz Vázquez

Sección de Estudios de Posgrado e Investigación (SEPI)- Escuela Superior de Ingeniería y Arquitectura (ESIA), Unidad Tecamachalco

Instituto Politécnico Nacional (IPN) Ciudad de México, México https://orcid.org/0000-0002-7302-180| aleyda.resendiz@gmail.com

\section{EL ESPACIO ENTRE LA PANTALLA Y LA ARQUITECTURA}

The Space between the Screen and Architecture

O espaço entre a tela e a arquitetura

Figura 0 De la película Ready Player One. Fuente: Spielberg (2016) y experiencia con realidad mixta dentro del Centro de Realidad Virtual de Brest, Francia. Fuente: Elaboración de la autora. 


\section{RESUMEN}

El artículo que sigue se refiere a la relación histórica y contemporánea que han desarrollado el cine y el espacio urbano-arquitectónico. Su objetivo es mostrar la influencia recíproca entre la realidad objetiva y la realidad virtual proyectadas en las películas de ciencia ficción Blade Runner, del director Ridley Scott (1982), y Ready player one, de Steven Spielberg (201 I), con respecto a la percepción actual del espacio arquitectónico. La idea de establecer la relación entre estas películas es destacar la prospectiva llevada a cabo por sus directores en torno a la interacción usuario-arquitectura y tecnología. Se citan, como antecedentes, algunas de las obras literarias y cinematográficas que abordan el tema de las ciudades posmodernas y las ciudades del futuro, ya sea desde una visión utópica o desde la perspectiva de una distopía. Metodológicamente, se realizó una revisión crítica de ambas cintas a partir de un esquema de análisis sobre la concepción de la arquitectura a través de su escenografía o puesta en escena (Zavala, 2003), así como de la similitud con la forma en que actualmente transitamos a través del espacio arquitectónico con el uso de tecnología de realidad mixta. De esta manera, los resultados exponen cómo la realidad mixta (física y virtual) impacta la percepción y el comportamiento de los usuarios dentro de los espacios físicos. La conclusión expresa la ineludible presencia de la realidad mixta en espacios tan complejos como son los del cine y los de la arquitectura.

Palabras clave: percepción, espacio, cine, realidad virtual, arquitectura.

\section{ABSTRACT}

This article presents the historical and contemporary relationship that cinema and urbanarchitectural space have developed. Its purpose is to show the reciprocal influence between objective and virtual reality projected in science fiction films like Blade Runner, by director Ridley Scott (1982), and Ready Player One, by Steven Spielberg (201 I), regarding the current perception of architectural space. The idea behind establishing the relationship between these films is highlighting the prospective used by their directors around user-architecture interaction and technology. Some of the literary and cinematographic works that address the topic of postmodern cities and the cities of the future are cited as background, either from a Utopian vision or from the perspective of a dystopia. Methodologically, a critical review of both films was carried out based on an analysis layout on the conception of architecture through its scenography or staging (Zavala, 2003), as well as the similarity with the way in which we currently travel through the architectural space with the use of mixed reality technology. In this way, the results show how mixed reality (physical and virtual) influences the perception and behavior of users within physical spaces. The conclusion expresses the inescapable presence of mixed reality in spaces as complex as those of cinema and architecture.

Keywords: perception, space, cinema, virtual reality, architecture.

\section{RESUMO}

O artigo apresenta a relação histórica e contemporânea que o cinema e o espaço urbanoarquitetônico têm mantido. $\bigcirc$ objetivo deste artigo é mostrar a influência recíproca entre a realidade objetiva e a realidade virtual projetada nos filmes de ficção científica Blade Runner, do diretor Ridley Scott (1982), e Ready player one, de Steven Spielberg (20 I I), no que diz respeito à percepção atual do espaço arquitetônico. A ideia de estabelecer a relação entre estes filmes é destacar a perspectiva adotada por seus diretores em torno da interação usuário-arquitetura e tecnologia. Algumas das obras literárias e cinematográficas que abordam a temática das cidades pós-modernas e das cidades do futuro são citadas como pano de fundo, seja a partir de uma visão utópica ou de uma perspectiva distópica. Metodologicamente, procedeu-se a uma revisão crítica de ambos os filmes a partir de um esquema de análise da concepção de arquitetura por meio de sua cenografia ou encenação (Zavala, 2003), bem como da semelhança com a forma como atualmente percorremos o espaço arquitetônico mediante tecnologias de realidade mista. Desta forma, os resultados mostram como a realidade mista (física e virtual) impacta a percepção e o comportamento dos usuários dentro dos espaços físicos. A conclusão expressa a presença inevitável da realidade mista em espaços tão complexos como os do cinema e da arquitetura.

Palavras-chave: percepção, espaço, cinema, realidade virtual, arquitetura. 
Los avances en informática aplicados a la representación, el desarrollo y la expresión dentro de los proyectos de arquitectura y cine han propiciado un acercamiento a la complejidad tridimensional de los productos cinematográficos y los objetos arquitectónicos virtuales. La relación entre la arquitectura actual, la realidad virtual y el cine es evidente en películas como Blade Runner, de Ridley Scott (1982) y Ready Player One, de Steven Spielberg (20 I8), cintas que constituyen el objeto de estudio de la investigación que aquí se expone. El resultado de las ideas arquitectónicas con aplicación de tecnología de realidad virtual en las películas ha generado un espacio que se percibe cotidianamente a través de aparatos inteligentes como los smartphones, las computadoras, las tabletas y los visores de realidad virtual (VR). El fenómeno que existe entre una pantalla y el espacio arquitectónico, llamado también espacio arquitectónico mixto (Palomo, 202I), se concibe, en palabras precisas, como la percepción simultánea del espacio físico con interacción en tiempo real con objetos virtuales.

La percepción del espacio arquitectónico mixto actual en el proceso de conocimiento y reconocimiento del espacio está definido por los estímulos recibidos de forma visual, auditiva y cinestésica y está condicionado por el conocimiento del espacio físico previo, el reconocimiento cultural de los espacios de transición, la permisividad de movimiento y la interacción con los elementos agregados tridimensionales virtuales (Palomo, 2021).

Para abordar lo que define la relación arquitectura-cine, el presente estudio comparó, dentro de las dos cintas revisadas, los escenarios virtuales con los reales. Se recurrió, para ello, al método de análisis cinematográfico propuesto por Lauro Zavala (2003), quien determina que es posible efectuar estudios tomando al cine como una categoría de análisis, en este caso a partir de la puesta en escena, es decir, a través de los escenarios.

Las observaciones realizadas se basaron en un esquema que permitió abstraer la percepción del espacio físico y mixto. La revisión detallada de las dos puestas en escena se focalizó en la búsqueda del espacio arquitectónico mixto, con el propósito de mostrar el impacto de la tecnología en la arquitectura y en la pantalla. Los resultados muestran la importancia de una transición en el quehacer arquitectónico y urbano hacia la concepción de espacios virtuales y mixtos.

La literatura, el cine y la arquitectura ilustran históricamente cómo se han influenciado mutuamente creando escenarios virtuales que llevan a imaginar realidades alternas y diferentes a la física. Las cintas analizadas exponen la presencia de la tecnología en la arquitectura, la estimulación con artefactos virtuales, incluso, la necesidad de vivir en una realidad virtual. Así, la revisión de Blade Runner y de Ready Player One se propone exponer la repercusión, social y cultural, de las nuevas tecnologías en los procesos de transformación de las dinámicas de relaciones sociales.

\section{Percepción del espacio físico y mixto}

El ser humano, desde su condición física y cultural, ha tenido que entender el espacio de diferentes maneras a través del tiempo, para habitarlo e interactuar con él. Ha debido construir límites y, al mismo tiempo, crear otros mundos generosos a la vista y los deseos de la imaginación. Esta convivencia con el mundo le ha forzado también a percibirlo. La percepción es el proceso cognoscitivo a través del cual un animal o un humano capta información proveniente del exterior (Real Academia 
de la Lengua Española [RAE], 2019), mediante los sistemas sensoriales. Los sentidos envían datos al cerebro para convertir dicha información en imágenes o ideas de lo que ha sido percibido. Es un proceso de concientización del ser en el mundo, o bien, del cuerpo en el mundo. El espacio arquitectónico tiene que ver con la delimitación que imponen los elementos construidos, y su definición espacial está dada por las cuatro dimensiones convencionales, alto, ancho, largo y tiempo; dimensiones analizadas por Calduch (200I) y acuñadas por Bruno Zevi (1969). Para Alberto Álvarez-Vallejo (2016), la percepción es una operación mental simple, histórica, no innata. Las operaciones preceptuales se desarrollan de acuerdo al nivel cognitivo de las personas: pueden ser sensoriales (a nivel de los órganos de los sentidos); sensitivas (que promueven el placer como lo sustancial); o teoréticas (donde se realizan las valoraciones artísticas de los aficionados ideales: artistas, arquitectos, urbanistas, etc.) (Álvarez-Vallejo, 20 16, p. 2).

El espacio virtual es aquel que se diferencia del espacio tangible en, al menos, un aspecto fundamental: la interacción digital con los objetos que lo habitan en el tiempo y espacio físico. El espacio virtual no se rige por las leyes físicas del espacio físico (Rodríguez, 2004), es decir, por las cuatro dimensiones físicas. El entorno interactivo digital se adapta a una circunstancia espacial por medio del uso de softwares especializados de realidad virtual, mediante los cuales se representan escenarios reales o imaginarios modelados por la tecnología llamada Virtual Reality Modeling Language.

La fusión de los elementos que configuran el espacio real y los elementos virtuales produce espacios arquitectónicos mixtos. La percepción dentro de un espacio arquitectónico mixto implica una nueva experiencia del usuario. La percepción dentro de un espacio arquitectónico mixto como un concepto complejo es una respuesta a un momento histórico, por lo que puede ser vista como una paradoja de la percepción y al proceso de significación. La concepción del espacio arquitectónico cambia y evoluciona ya que, aunque se entiende dentro de una dimensión física tangible, el concepto se amplía a una dimensión virtual. E uso de la realidad mixta en el espacio arquitectónico modifica la percepción visual y cinestésica del usuario, sobre todo en términos de reconocimiento y permisividad de movimiento.

El efecto del uso de la realidad virtual (Figura I) en la percepción del espacio arquitectónico, en el proceso de conocimiento y reconocimiento del espacio, está definido por los estímulos recibidos de forma visual, auditiva y cinestésica y está condicionado por el conocimiento del espacio físico previo, el reconocimiento cultural de los espacios de transición (circulaciones) y la permisividad de movimiento, es decir, los umbrales entre lo público y lo privado para transitar dentro del espacio arquitectónico (Figura 2). Por ello, la interpretación del espacio físico y virtual (espacio arquitectónico mixto) tiene que ver con los conocimientos y experiencias previas sobre el espacio físico, el espacio virtual y el reconocimiento de los elementos agregados tridimensionales virtuales. La interpretación de lo simulado puede generar una experiencia auténtica, que integre la percepción de los estímulos inmediatos de ambas realidades en un mismo espacio (Palomo, 2021).

\section{El cine futurista en la Arquitectura (1900-2020)}

La percepción de la ciudad del futuro ha sido un tema que se ha desarrollado de la mano de los cambios sociales y los avances tecnológicos. Mantiene una 

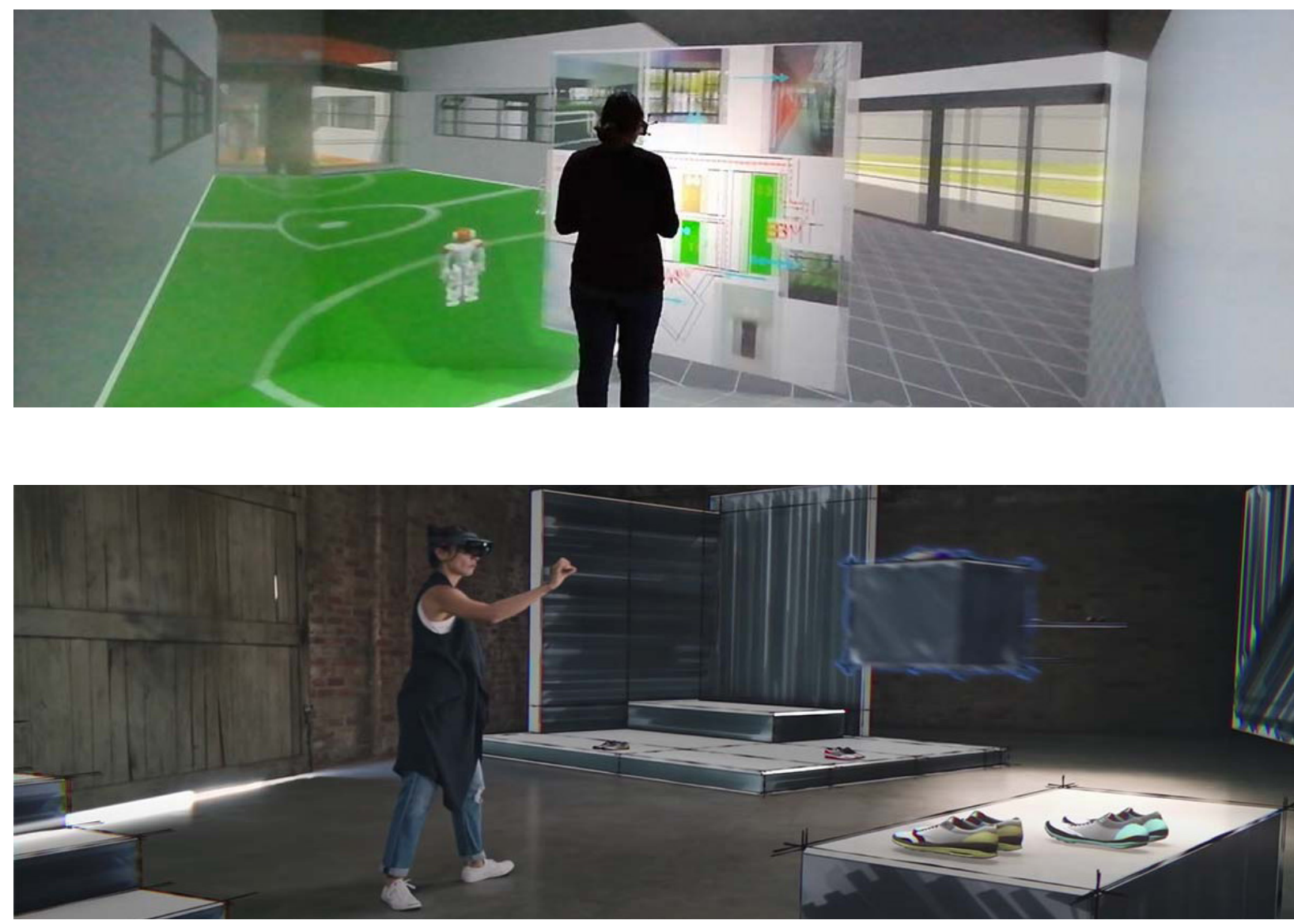

Figura 1 Experiencia con realidad virtual dentro del CAVE en el Centro de Realidad Virtual de Brest, Francia. Fuente: Elaboración de la autora.

Figura 2 Experiencia con realidad mixta. Fuente: Visualizando el futuro con Windows Mixed Reality (2016).

1 Según la RAE, una distopia es una representación ficticia de una sociedad futura de características negativas causantes de la alienación humana. Una distopía o antiutopía es una sociedad ficticia indeseable en sí misma (Wikipedia. https://dle.rae.es/ distop\%C3\%ADa). relación estrecha con la literatura, que parece anticipar la manera de recorrer sus territorios, desde los visibles hasta los virtuales. Desde la novela de Julio Verne, "Paris au XXe siècle "( I 863), hasta Ready player one, de Ernest Cline (20 I I), la literatura ha mostrado escenarios del mundo futuro con prospectivas positivas o negativas en los ámbitos de lo social, económico y arquitectónico. La literatura, desde el siglo XIX a la fecha, expone la inquietud general de los habitantes con respecto al futuro de las ciudades contemporáneas, muchas de ellas promovidas en la era industrial y, actualmente, insertas en una era tecnológica, bursátil, hiperreal (López Rangel, 2006, p. 8).

La influencia de los momentos históricos y el cambio en la percepción del espacio permitieron que, en el siglo XIX, algunos escritores como Charles Dickens, Gustave Flaubert, y Víctor Hugo describieran las ciudades de su época a través de sus narraciones. Para el siglo XX, la percepción y descripción de las ciudades posmodernas o futuristas se perciben en las novelas de Julio Verne (París en el siglo $X X$ ), John Dos Passos (Manhattan Transfer) y Alfred Döblin (Berlín Alexanderplatz). Más tarde, aparecen los autores que describen las ciudades futuras como una distopía', como ocurre con Aldous Huxley (Un mundo feliz), George Orwell (1984) y Ray Bradbury (Fahrenheit 45/).

Con la llegada del cine, la literatura se transformó, a través de sus adaptaciones, en una colectividad de imágenes y producciones de las realidades previstas para los mundos futuros, convirtiéndose en un referente de la configuración del espacio y de las ciudades. La manifestación visual en el cine ha retratado y otorgado imágenes con percepciones distintas sobre los espacios físicos y 


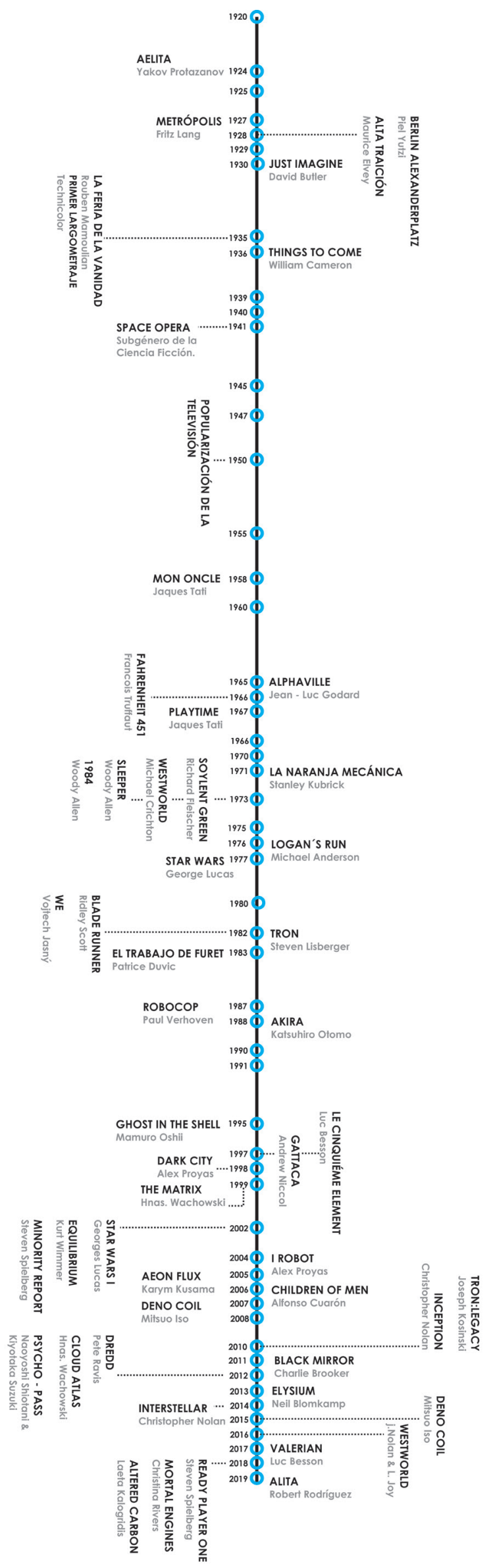

Figura 3 Línea del tiempo Cine + Literatura. Fuente: Elaboración de la autora. 
virtuales. La percepción de la tecnología y sus diversos impactos en la sociedad es abordada en películas como Metrópolis (Fritz Lang), Matrix (Lana y Lilly Wachowski), Minority report (Steven Spielberg), El origen (Christopher Nolan) y Tomorrowland (Brad Bird).

Entre los directores de cine de ciencia ficción ${ }^{2}$ que han convertido obras literarias en obras cinematográficas a partir de temas relacionados con las ciudades posmodernas o futuras, se puede mencionar a: William Cameron Menzies, con Things to Come (1936); Francois Truffaut, con Fahrenheit 45 I (1966), Michael Radford con 1984 ( 1984 ); Stanley Kubrick, con La naranja mecánica ( 197 I); Steven Spielberg, con Ready Player One (20 I I); Ridley Scott con Blade Runner ( 1982) y Blade Runner 2049 (2017) -adaptaciones de la novela iSueñan los androides con ovejas eléctricas?, de Phillip K. Dick-; Christopher Nolan con Inception (20 I0), una obra de él mismo; y Joseph Kosinski con Tron: Legacy (2010) (Figura 3).

La ciencia ficción del espacio futuro arquitectónico-urbano, por su parte, encontró una nueva dimensión: la de visualizar una realidad a través de los ojos sin presenciarla de forma física, permitiendo al espectador sumergirse en ambientes e imágenes en movimiento, cumpliendo así ciertas fantasías.

Dicha visualización tomó fuerza cuando algunos arquitectos se vieron influenciados por los avances tecnológicos y la implementación de la tecnología en la arquitectura. La visualización de los avances tecnológicos llevó a imágenes la realidad de una prospectiva utópica o distópica de la configuración espacial del espacio interior y urbano. Los arquitectos con tendencias futuristas realizaron manifiestos y propuestas gráficas de la ciudad futura. He ahí los casos de la Gläserne Kette (cadena de cristal) de Bruno Taut (Calatrava, 200 I); La Ciudad de voladora (Khan-Magomedov, 20 I I), de Krutikov (1928); la Ciudad sobre resortes (Prokopljevic, 2020) de Anton Lavinskii propuesta en 1921; pero también los de Le Corbusier, con la planeación de la Cité Radieuse, realizada el año 1933, en Marsella (Blasco, 2013); Lucio Costa y Óscar Niemeyer, con el diseño de Brasilia de 1956 (Chaparro, 2013); la planeación de las ciudades de Kevin Lynch de 1960 (Lynch, 1998); Antonio Sant’Elia con La ciudad futurista de 1914 (Barona, 2009), que influencia principalmente a Archigram (1964) en The plug in city, capsule homes, The walking city; y Paolo Soleri, con su modelo de ciudad ecológica de 1970 (Franco, 2013), para ser construida en el espacio (Arcología "Arcosanti").

En este contexto, Peter Cook explica la relación entre la arquitectura y la ciencia ficción en la publicación Archigram 4, de 1964. Allí expone la necesidad de renovar la profesión del arquitecto, y la capacidad de producir la imagen arquitectónica en la ciencia ficción. Se puede mencionar a Kiyonori Kikutake como un arquitecto con gran influencia de la visión de Archigram, cuyo diseño basado en megaestructuras fue rescatado por Douglas Trumbull para el filme Silent Running (1972). La ideología de Archigram marcó una transición en la forma de visualizar la arquitectura producida en el cine de ciencia ficción en los años 70. Películas de ciencia ficción como Star

2 La ciencia ficción es un género literario caracterizado por una narración que propone una hipótesis sobre lo que podría ser el futuro y / o universos desconocidos, partiendo de los conocimientos actuales (científicos, tecnológicos, etnológicos, etc.) (Bassa y Freixas, 1993).
Wars (1977) y Battlestar Galactica (1978), mostraron megaestructuras con soluciones tecnológicas para su funcionamiento. El cine se convirtió en el espacio donde los arquitectos podían realizar obras con una visión futura del espacio y de la ciudad. En la década de 2000, el cine futurista mostraba el espacio público obscuro y con edificaciones altas, convirtiendo a las superestructuras en protagonistas. En el mundo físico, lo mismo hacían los arquitectos Jean Nouvel, con sus edificios Fundación Cartier (1984), Louvre Abu Dabi (2017) y el Museo nacional de Qatar (2019); así como Rem Koolhaas, con la Biblioteca central de Seattle (2002) y la Sede de televisión central 
de China (2004); edificios con texturas superpuestas, resueltas con estructuras imponentes.

Los arquitectos y los directores de cine trabajan con ejes de diseño similares. Ambos investigan, crean ambientes y configuran el espacio, sólo que en el espacio físico la experiencia de transición es lo más relevante y está influida por el tiempo. En cambio, en el cine la experiencia es manipulada por los planos en que aparecen los objetos ${ }^{3}$. En el periodo de 1970- 1980 ocurrió un cambio radical en la percepción del espacio y el tiempo con la incorporación del uso de la informática y la interacción persona-computadora; lo que ha perdurado hasta la actualidad, cuando se suma la posibilidad de inmersión a una realidad simultánea con la realidad física y la realidad mixta (RM).

Los arquitectos han buscado ver realizado el futuro en sus construcciones. Así, la relación de la arquitectura y la ciencia ficción es estrecha. Por un lado, el concepto de la arquitectura ha evolucionado y los arquitectos han encontrado otros campos de desarrollo y de práctica como el entretenimiento (videojuegos y ambientes virtuales), la publicidad, el cine y el diseño de ambientes de realidad mixta. La era digital ha permitido configurar espacios de forma virtual, lo cual conlleva a modelarlos en programas especializados. La calidad en la visualización del objeto arquitectónico en un ambiente virtual ha mejorado la producción de herramientas digitales, por lo que los diseñadores pueden realizar edificios más sofisticados, que antes solo la ciencia ficción podía mostrar en el cine. El concepto de la arquitectura actual depende de la tecnología visual y la tecnología constructiva, lo que permite al arquitecto realizar la obra y, al mismo tiempo, le brinda una mayor permeabilidad para generar intercambios y apropiaciones de dos realidades simultáneas, la física y la virtual.

Es importante recordar que las relaciones espaciales están sometidas a una constante transformación (Harvey, 200 I). El cambio constante de la tecnología y la aplicación al espacio y a la configuración del espacio tienen el mismo objetivo de transformar el espacio y la relación con él usuario.

Desde estas perspectivas es que se llevó a cabo una revisión crítica de las ya citadas dos cintas: Blade Runner y Ready Player One. El análisis de la concepción de la arquitectura a través de su escenografía o puesta en escena (Zavala, 2003), se focalizó en la forma en que actualmente transitamos a través del espacio arquitectónico con el uso de tecnología de realidad mixta.

\section{La Arquitectura en Blade Runner}

Desde la fecha de su estreno, la influencia de Blade Runner (1982) en el cine y en la percepción del futuro en la escenografía urbana ha sido innegable (Sammon, $2017)$. La especulación con el futuro posible, donde la tecnología funciona como una segunda piel adherida a la arquitectura, representa un paradigma para conceptualizar la mutación futura del objeto arquitectónico (Figuras 4 y 5).

La arquitectura de la obra cinematográfica Blade Runner fue realizada en base a pinturas de Edward Hopper y la obra de Moebius. Dicho por Ridley Scott, según Portella (2019), la influencia de la escenografía de la película proviene de las pinturas de Edward Hopper, que muestran la visión futura de Hong Kong y Nueva York y los paisajes industriales de Tyneside y Teesside. La referencia más importante para el director, en la concepción de los escenarios de la película, fue la revista francesa Metal

\section{METODOLOGÍA}


4 Mead era diseñador en la industria automovilística, por ello fue contratado en el diseño de autos futuristas, sin embargo, tuvo participación en muchos otros aspectos de la película (Sammon, 2017).

5 Archigram presentó un catalizador que los arquitectos utilizaron para tener una visión de la arquitectura en fusión con la tecnología. Richard Rogers, Michael Hopkins y Nicholas Grimshaw dieron vida al nacimiento del High Tech. La propuesta de Archigram se convirtió en una consecuencia del cuestionamiento a las convenciones arquitectónicas. En la realidad física, el movimiento High Tech mostró que la tecnología podía ser tangible, y el diseño la incorporó a los nuevos edificios.
Hurlant y la obra de Moebius, The long tomorrow, de Jean Geraud (1975), proyectada en los dibujos de Syd Mead ${ }^{4}$ (Sammon, 2017) (Figura 6).

La idea, dentro de dicha película, de crear capas sobre capas en la arquitectura, genera una visión de la ciudad cada vez más cargada, que se puede entender como un reflejo de la realidad, pues la arquitectura ciertamente sufre o se transforma con la adhesión de estilos y tendencias en las épocas sucesivas. La respuesta al cambio socio-tecnológico, a inicios de 1960, permitió diversificar las propuestas en el diseño arquitectónico ${ }^{5}$. La película muestra la influencia de la tecnología en lo físico, no en lo virtual, sin embargo, deja abierta la posibilidad de la futura mutación y pérdida de la apreciación física de la arquitectura por causa de la intervención tecnológica. El paisaje urbano de Blade Runner entrevé la pérdida de la percepción del vacío configurado. Desde este enfoque, se advierte la acumulación de elementos constructivos y tecnológicos adheridos a las fachadas.

Blade Runner nació en un ambiente de arquitectura posmoderna. En los años 80 , el posmodernismo recupera las formas de la historia como un instrumento de vinculación con la memoria tradicional. La arquitectura en esta cinta es ecléctica e iconográfica, con columnas clásicas y letreros iluminados. La ciudad se convierte en un atractivo ordinario y puede entenderse desde la filosofía de Venturi (1972), en el sentido de percibir la ciudad como un aparador, es decir, los anuncios como señales gráficas del paisaje urbano.

Esta percepción se refleja en un paisaje en el que se mezclan columnas griegas y romanas, como un recordatorio de la ciudad perfecta o del paraíso perdido. Según Fernández (2014), el contexto urbano está envuelto en un ambiente de tristeza y la arquitectura es el punto de enfoque. En el ambiente de Blade Runner se siente la opresión y frustración mediante el constante ruido de cláxones, gritos, gases y las proclamas publicitarias en la ciudad definida por un urbanismo caótico y decadente, de guetos con actividades económicas concretas. En el eclecticismo arquitectónico se incorporan dos edificios: la Casa Ennis (1924), de Frank LloydWright, y los almacenes del edificio Bradbury ( 1893 ), de George H.Wyman, ubicados en la ciudad de los Ángeles. Ambas construcciones son incluidas por el director dentro del guion, y al evitar construcciones más futuristas ha conseguido que la película no haya sufrido de un envejecimiento prematuro.

\section{La Arquitectura en Ready Player One. El Metaverso}

El concepto de "Metaverso" se ha utilizado desde que salió a la luz la novela de ciencia ficción Snow Crash, escrita por Neal Stephenson en 1992. La novela maneja el concepto de Metaverso como un ciberespacio en torno a nuevas tecnologías y a la interacción masiva de diferentes usuarios con identidades distintas a la del mundo físico. Stephenson (2000) diseñó una extensión lógica de las redes informáticas actuales mostrando su impacto social y cultural. Más tarde, la película Ready Player One (20 I 6), basada en el best-seller de Ernst Cline (20 I I), utilizó el concepto Metaverso para exponer una realidad alterna a la física.

La obra de Cline (201 I) narra la historia de Wade Watts, un adolescente que vive en el distópico año 2045. En el guion existe una sociedad cuyo comportamiento es desinteresado e indiferente hacia los aspectos sociales, políticos y económicos. El personaje de James Halliday, quien luego se convierte en un magnate, crea un videojuego multijugador masivo online (MMO) de realidad virtual, al que llama OASIS, donde casi toda la población está inmersa; el videojuego 

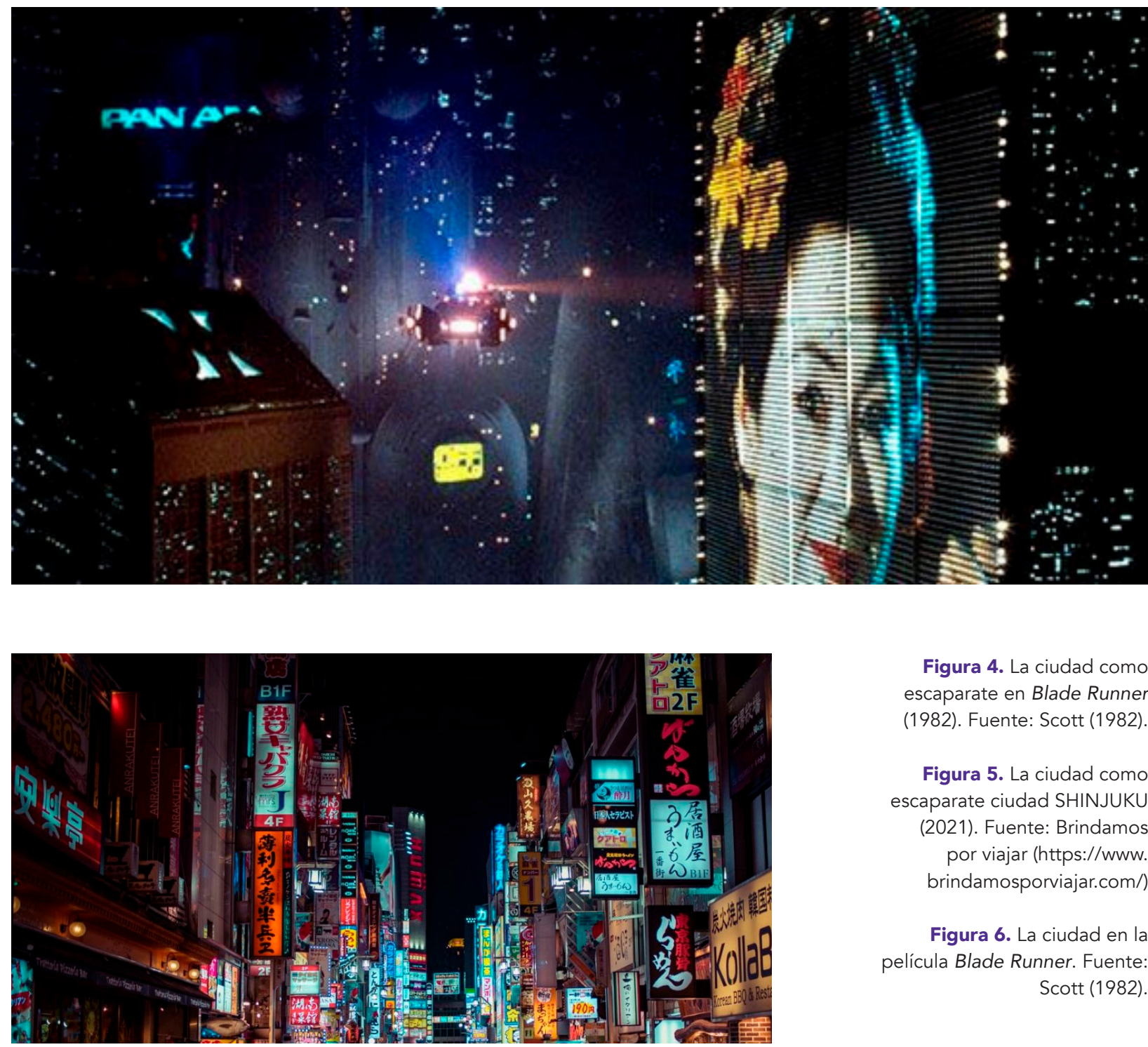

Figura 4. La ciudad como escaparate en Blade Runner (1982). Fuente: Scott (1982).

Figura 5. La ciudad como escaparate ciudad SHINJUKU (2021). Fuente: Brindamos por viajar (https://www.

brindamosporviajar.com/)

Figura 6. La ciudad en la película Blade Runner. Fuente: Scott (1982).

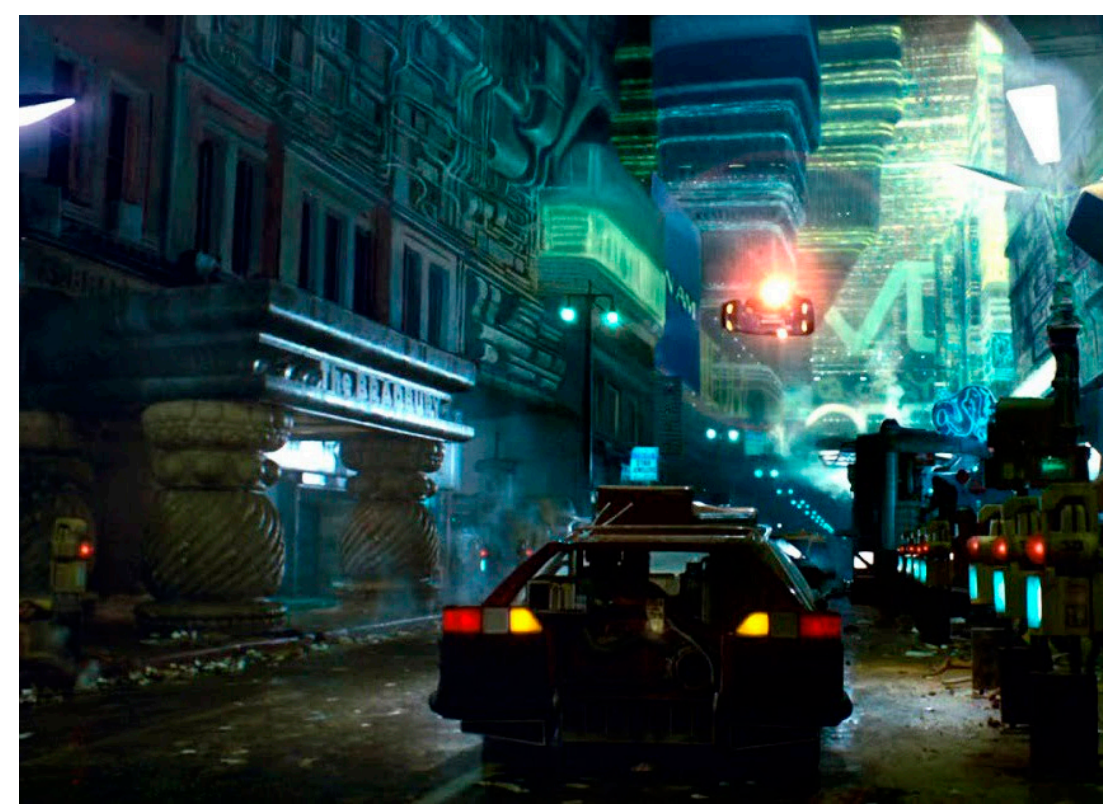




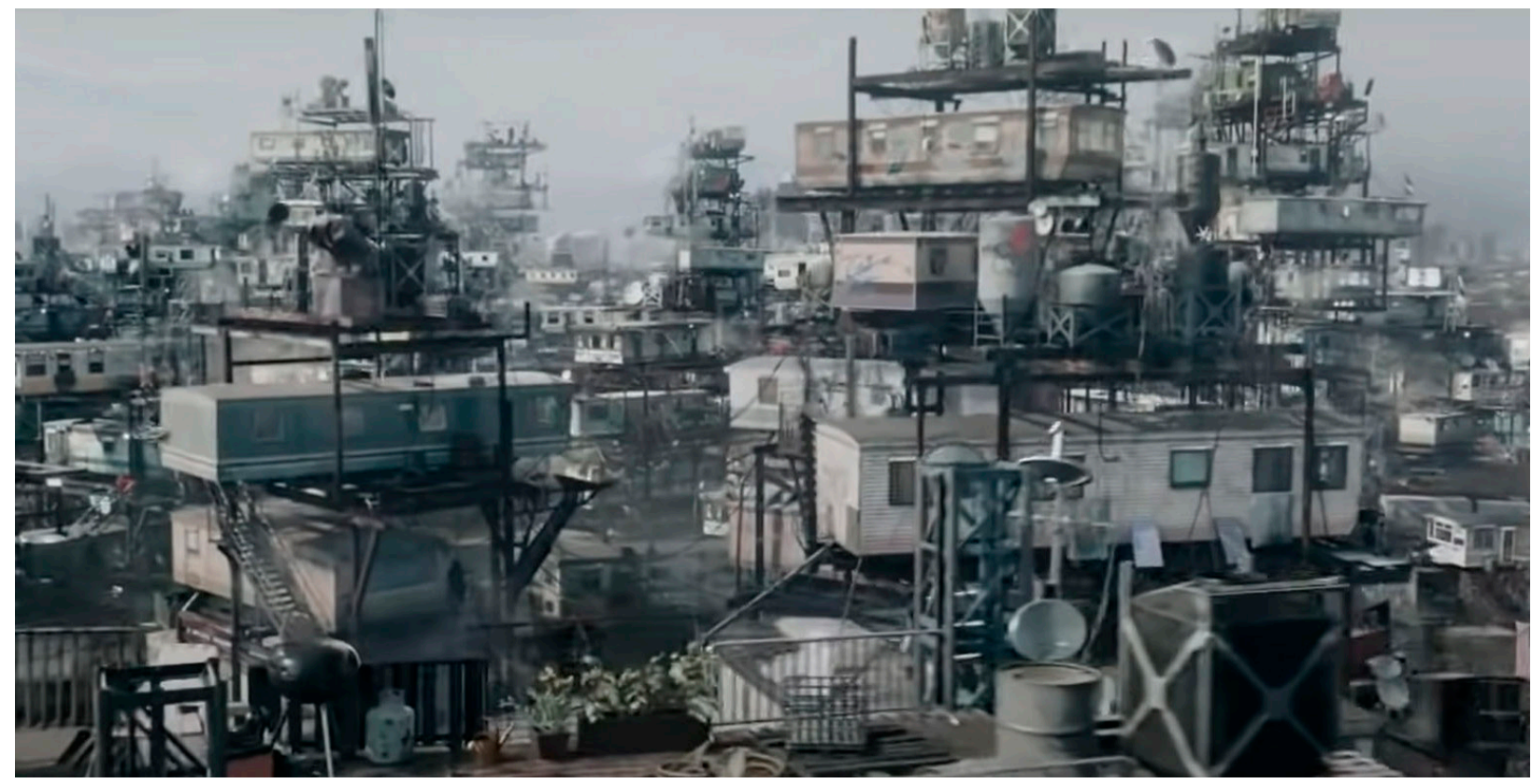

Figura 7 Las torres de la película Ready Player One. Fuente: Spielberg (2016).

Figura 8 La ciudad de Kowloon. Fuente: Mead (2017)

Figura 9 Vivienda al oeste de Estados Unidos (2021). Fuente: Díez (2021).
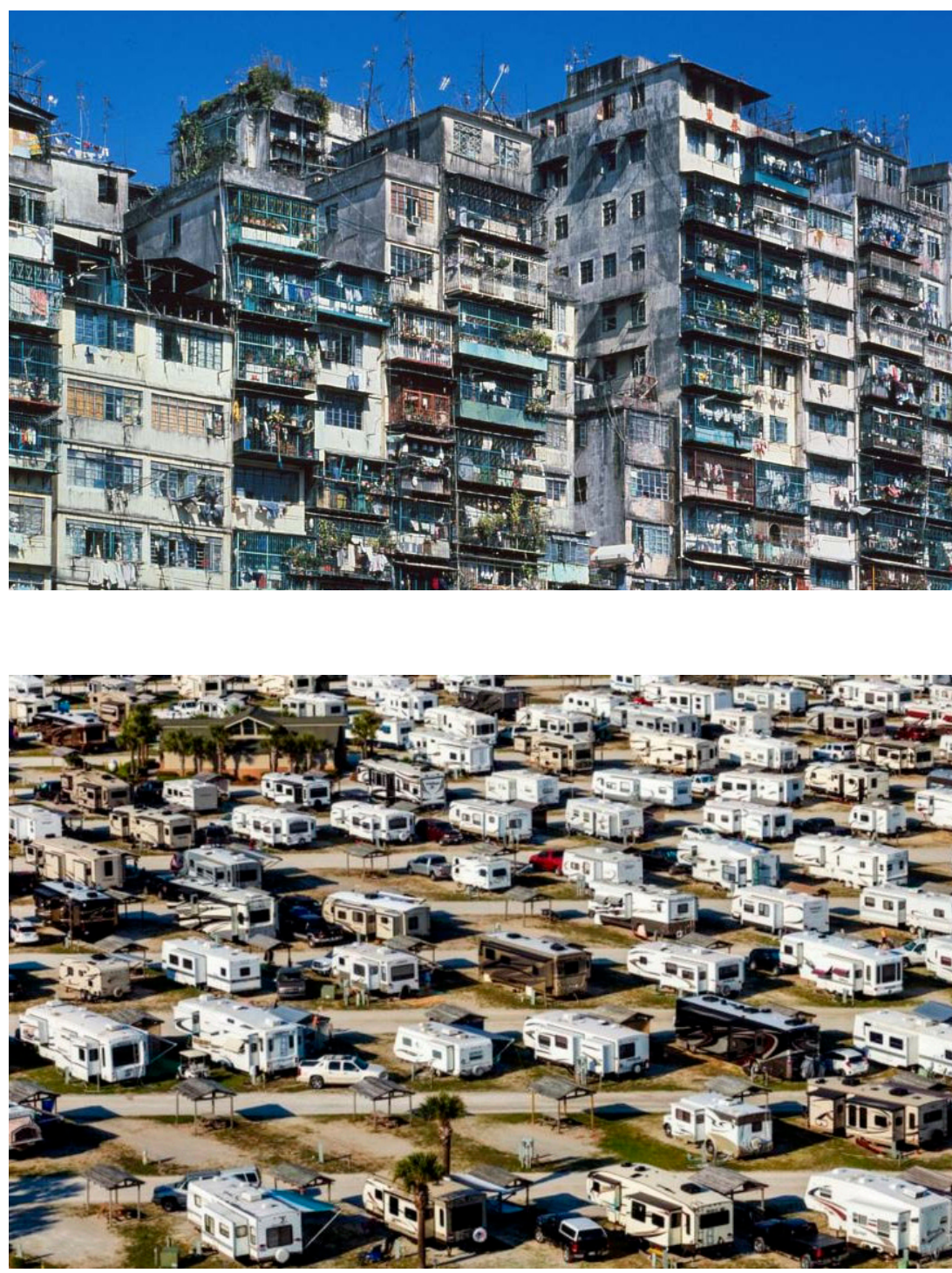
se convierte en una vía de escape de la realidad. La película presenta una sociedad nostálgica, el personaje principal,Wade, un adolescente inmerso en un ciberespacio, transita a través de un territorio virtual tratando de conseguir el huevo de pascua del juego (Lahoz, 2019).

En la cinta se pueden distinguir tres espacios del mundo real: las torres, donde vive Wade; la resistencia y las oficinas de IOI, además de los espacios diferenciados que definen las distinciones sociales entre los poderosos y la clase empobrecida. Los escenarios reflejan el futuro distópico desde los ojos del protagonista, donde los habitantes buscan una salida fácil y no una solución en el mundo real. Los espacios físicos muestran la actitud de la sociedad, pues se ha abandonado la idea de convivir con el mundo real. Los personajes de la película no creen que tenga sentido luchar por un mundo al que ya han dado por muerto, cuando tienen una opción más atractiva en todos los sentidos.

Las torres (The stacks) constituyen el lugar donde Wade vive con su tía (Figura 7). Los edificios expresan la decadencia social de los habitantes, una visión distópica del futuro de la convivencia en una sociedad. Los módulos apilados sin orden y sujetos de una estructura metálica, que se presentan como edificios a lo largo de un suburbio, evidencian el desinterés por la imagen urbana y un desprecio por la realidad. Son andamios habitables. Hay una combinación de desinterés por el espacio físico y la utilización de tecnología de última generación; se puede decir que los edificios son una especie de favelas, una configuración espacial sin privacidad. El espacio de convivencia cordial es un espacio dinámico, es el espacio virtual.

El diseñador de producción de Ready player one, Adam Stockhausen, reconoce que se inspiró en la ciudad amurallada de Kowloon, en Hong Kong (Desowitz, 20 I8). La ciudad de Columbus, en Ohio, aparece en una vista aérea como una manzana sobrepoblada similar a la de la ciudad de Kowloon (Figura 8) o a la vivienda al oeste de Estados Unidos (Figura 9). La arquitectura clip-on, que se puede visualizar en las torres, tiene una referencia muy clara similar a la arquitectura de Peter Cook y el diseño Plug-in City (1964) de Archigram. La arquitectura del espacio virtual en Ready player one se llama OASIS, Ontologically Anthropocentric Sensory Inmersive Simulation, en español, Simulación de Inmersión Sensorial Ontológica Antropocéntrica. Es una solución a la supervivencia de la sociedad, la oportunidad de vivir dos realidades diferentes, donde desaparecen las preocupaciones diarias y donde todo es posible. Lo anterior puede apreciarse en la configuración del espacio y las posibilidades de ser y estar en donde se quiera.

En el libro y en la película Ready Player One, el Metaverso es un espacio virtual en el que los usuarios disfrutan, y donde pueden verse y expresarse como deseen. El Metaverso es una visión futura del espacio virtual, es un núcleo de información en crecimiento y evolución, que contiene todo lo que existe en nuestros días en internet ${ }^{6}$

La realidad virtual como tecnología en el área de la informática ha abierto una serie de posibilidades en tiempo real. La idea del metaverso es un proyecto con amplias oportunidades en el campo de la comunicación, la arquitectura, la medicina, el entretenimiento y la investigación. En el mundo virtual, como lo muestra Ready Player One, se puede ser o hacer o lo que se quiera.

Los límites tecnológicos se van superando en función de las ideas generadoras de soluciones a través de la experimentación. El enfoque de crear mundos o ciudades virtuales ${ }^{7}$ alternos a la realidad física tiene como principios los siguientes: la persistencia (de lo que se crea o compra mientras el Metaverso permanezca), la escala masiva (para que puedan interactuar de I a 100 personas al mismo tiempo), la accesibilidad

6 En la realidad que vivimos, las empresas Epic Games y Sony vieron la posibilidad de crear un Metaverso. Ambas empresas plantearon una colaboración e invirtieron una considerable suma, a lo que llaman un negocio entre la creatividad y la tecnología, encaminado a construir un ecosistema digital más amplio y accesible para los consumidores y creadores de contenidos virtuales (Todo lo que sabemos, 2020).

7 Algunos ejemplos son los videojuegos Minecraft y Fortnite. 
e interoperabilidad (desde cualquier dispositivo y lugar, saltando de una plataforma o mundo virtual a otro), y la economía virtual con impacto social (el dinero que se genera en ese mundo existe).

La realidad actual demuestra que tal vez las ciudades no sufrirán más intervenciones físicas, sino que se construirán de forma virtual. El espacio físico se visitará de forma simultánea con los mundos virtuales.

\section{RESULTADOS}

Las películas descritas, cuyas temáticas se vinculan con el impacto de la tecnología en la percepción del espacio urbano y arquitectónico, revelan la influencia recíproca que existe entre la realidad objetiva y la realidad virtual, sobre todo en términos de la alienación en la apreciación de la arquitectura y de la convivencia simultánea con una realidad virtual. Manifiestan, además, la transición a la virtualidad que, en la primera cinta se desarrolla en un tono más mercadológico y mediante una priorización de objetos tecnológicos sobre la arquitectura. En la segunda ocurre una franca transición hacia una realidad no física, que posibilita experiencias de vida, en donde el espacio físico no es protagonista.

Concretamente, este artículo se enfoca, como se ha visto, en la percepción futura de la arquitectura y su interacción con tecnología de realidad mixta. De esta forma, debe señalarse que la relación que experimentamos durante el proceso de percepción del espacio arquitectónico tiene que ver con diferentes aspectos, entre los que destacan dos: el uso del espacio, es decir, para qué fue diseñado el espacio (transitar estar, cocinar, etc.) y la dinámica de uso que un usuario establece en él. El uso de la tecnología en la transición del espacio ha generado un fenómeno de desapego en la percepción del espacio arquitectónico y el espacio urbano (Palomo, 202I). En ese marco, la relación que se establece en estas películas destaca la prospectiva realizada por los directores en el tema de la interacción usuario-arquitectura y tecnología, ya que, por un lado, en Blade Runner se observa una percepción nublada de la arquitectura (muy cercana a la realidad, por cierto, donde la mercadotecnia y la tecnología son más importantes que el edificio); y, por otro, en Ready Player One se presenta un total desapego al espacio físico y un tránsito hacia el uso del espacio virtual que se convierte, en definitiva, en el mundo primario, con lo cual se ve abandonada la percepción del espacio físico.

En la película Blade Runner (1982) se pueden identificar seis aspectos que en la actualidad experimentamos. Primero, ciudades sobrepobladas en las que, para el usuario que se desplaza a pie, el contexto inmediato está conformado por comercios, o bien, comercios informales que impiden la percepción total del espacio urbano. Segundo, el uso de la tecnología como segunda piel de edificios viejos o nuevos. Tercero, la arquitectura aparece en segundo plano en la transición de un lugar a otro, porque el espacio ya no es primordial. Cuarto, aun cuando nuestra percepción visual es la que completa la sensación que nos transmite un espacio, esos estímulos están centrados en artefactos que muestran imágenes fuera de nuestra realidad. Quinto, sólo los espacios destinados a actividades en donde se permanece en reposo y relajación, se presentan carentes de tecnología, siendo, además -otra condición similar a la realidad-, espacios privilegiados de la población con alto nivel adquisitivo. Sexto, la tecnología nueva denota frialdad.

En el filme Ready Player One (20 I I), en tanto, se reconoce otra dinámica afín al mundo contemporáneo: la necesidad de vivir otra realidad, la virtual, dadas las circunstancias sociales, políticas, económicas y la accesibilidad (los usuarios que se 
encuentran conectados en la red son susceptibles a interactuar con todos los que se encuentren dentro de internet). De este modo, aparece la posibilidad de presenciar otros espacios, utilizando artefactos que permiten visualizarlos y transitar a través de ellos, aun estando a kilómetros del espacio que se observa.

La influencia recíproca entre la realidad objetiva y la realidad virtual proyectadas en las películas de ciencia ficción Blade Runnery Ready Player One recae en la percepción del espacio arquitectónico construido y en el diseño de los espacios futuros.

El uso de la tecnología dentro del espacio arquitectónico se ha determinado por la dinámica y la realización de diversas actividades cotidianas, sociales, educativas y recreativas. En nuestros días, la tecnología aplicada a diversos procesos productivos dentro del espacio arquitectónico, incluidos el arte, la arquitectura y la cinematografía es impulsora en la optimización de los procesos para la creación y construcción de los espacios.

En la era de la transición de lo físico a lo virtual, es importante plantear la inmersión en diferentes realidades: por una parte, está la realidad que se conoce como física y tangible, de la que se tiene un conocimiento cotidiano; por otra, se encuentra la realidad construida a partir de la inmersión en la realidad virtual, que da oportunidad a llevar la experiencia de un espacio físico a la potencialización del espacio con elementos virtuales. En pocas palabras, la tecnología aplicada al espacio físico es otra realidad que podremos experimentar.

El paso de una visión en la que predomina el concepto del espacio arquitectónico real a una visión compleja del espacio arquitectónico mixto es un proceso continuo que se vive en este momento de la historia. La realidad mixta permite al usuario entender tanto el mundo virtual como su mundo primario. El usuario solo se relaciona con el espacio físico a través de elementos del ambiente que definen el conocimiento del espacio como la luz, los objetos reales, los estímulos auditivos y los elementos construidos que configuran los vacíos interiores para transitar.

La percepción dentro de un espacio arquitectónico mixto implica una experiencia innovadora. La concepción del espacio arquitectónico cambia y evoluciona, el concepto se amplía a una dimensión virtual.

El uso de la realidad virtual y la realidad mixta constituye un hecho inevitable, con sus consecuentes ventajas y desventajas. La transición que se produce desde el espacio arquitectónico hasta una visión del espacio arquitectónico mixto es un evento al cual asistiremos en los años próximos, con certeza. Por ello, la arquitectura del futuro debe ser concebida diseñando el espacio arquitectónico mixto (Palomo, 202 I), donde se encuentren la realidad física y virtual de forma simultánea y en tiempo real. Ello conduce a considerar la práctica de la arquitectura de una forma contemporánea y compleja. La tecnología de realidad virtual se ha convertido en una construcción determinada que nace de un aspecto social, pero que, a la vez, es el terreno ideal para debatir sobre las similitudes y las diferencias entre la percepción del espacio real y el espacio creado virtual. Es el campo de una dicotomía que generará, sin duda, nuevas epistemologías al respecto. En este sentido, la realidad mixta será un factor en las variaciones futuras en la percepción cinestésica y visual del espacio arquitectónico; factor que influirá en términos de reconocimiento y permisividad del movimiento y sus límites 9 . Solo queda esperar el arribo de la realidad mixta, como un evento inminente que modificará el uso diario de los espacios arquitectónicos y de la vida en general.

6 Ello ocurrirá, desde luego, en
circunstancias específicas donde
el mundo real se encuentre
integrado a los elementos
digitales que modificarán su
experiencia durante la transición
entre los dos espacios que se
mencionan. Es decir, en medio
de un territorio híbrido.

\section{CONCLUSIÓN}




\section{REFERENCIAS BIBLIOGRAFICAS}

Albrecht, D. (2000). Designing dreams: Modern architecture in the movies. Santa Mónica: Hennessey + Ingalls. Barber.

Álvarez-Vallejo, A. (2016). Percepción visual. Una discusión urbana y arquitectónica. Revista Legado de Arquitectura y Diseño, I (19). Recuperado de https:// www.redalyc.org/journal/4779/47795 I060008/47795 I060008.pdf

Archigram (1964). Recuperado de http://www.archigram.net/index.html

Baraona, E. (2009). Recordando a Antonio Sant’Elia. Archdaily. Recuperado de https://www.archdaily.mx/mx/02- I 9575/recordando-a-antoniosant\%25e2\%2580\%2599elia

Bassa, J. y Freixas, R. ( 1993). El cine de ciencia ficción. Una aproximación. Barcelona: Paidós.Blasco, J.A. (20 I3). El sueño de Le Corbusier que se convirtió en pesadilla: de la Unité de habitation a los Grands ensembles (en Marsella, por ejemplo). Urban Networks. Recuperado de http://urban-networks.blogspot.com/2013/08/el-suenode-le-corbusier-que-se.html

Calduch, J. (200 I). Temas de composición arquitectónica: espacio y lugar. España: ECU.

Calatrava, J. (200 I). La cadena de cristal. Minerva, ( 18). Recuperado de https:// cbamadrid.es/revistaminerva/articulo.php?id $=500$

Chaparro, O. (20 I3). Brasilia: Una utopía moderna. 1956- 1960. Lucio Costa/ Óscar Niemeyer. Proyectos 7/Proyectos 8. Recuperado de https://proyectos4etsa. wordpress.com/2013/0 1/30/brasilia-una-utopia-moderna- 1956-1960-luciocostaoscar-niemeyer/

Cline, E. (201 I). Ready player one. Nueva York: Crown publishing group. Cook, P. (1 964). The zoom issue. Amazing Archigram 4. Recuperado de http:// architecturewithoutarchitecture.blogspot.com/20 I 2/I 2/the-amazing-archigram-4zoom-issue- | 964.html

Desowitz, B. (20 18). The Secret Weapon on 'Ready Player One' and 'Isle of Dogs': Production Designer Adam Stockhausen. Recuperado de https://www.indiewire. com/20 18/03/steven-spielberg-wes-anderson-ready-player-one-isle-of-dogsproduction-designer-adam-stockhausen-animation- I201944907/

Díez, B. (2021). Oscar 2021: "Nomadland", así es la vida de los miles de personas que viven y viajan en casas rodantes por E.E.U.U. BBC News. Recuperado de https://www.bbc.com/mundo/noticias-internacional-56598232

Fernández, T. (20|4). Una Arquitectura distópica-El universo de Blade Runner. Cosas de arquitectos. Recuperado de https://www.cosasdearquitectos.com/20 I 4/04/ una-arquitectura-distopica-el-universo-de-blade-runner/

Franco, J. (2013). Cine y Arquitectura. "La visión de Paolo Soleri: Profeta del desierto". Archdaily. Recuperado de https:/www.archdaily.mx/mx/02-29 I339/cine-yarquitectura-la-vision-de-paolo-soleri-profeta-en-el-desierto

Harvey, D. (200 I). Espacios del capital. Hacia una geografía crítica. Madrid: Akal. Jacobs, S. (2007). La casa equivocada: La arquitectura de Alfred Hitchcock. Rotterdam: 010 Editores. 
Khan - Magomedov, S. (20 I I). Georgii Krutikov. La ciudad voladora. The charnel house. Recuperado de https:/thecharnelhouse.org/tag/georgii-krutikov/

Lahoz, A. (2019). Mundos virtuales. Arquitectura, cine y videojuegos. El caso de Ready player one. Tesis de magíster. Universidad de Zaragoza. Recuperado de https://zaguan. unizar.es/record/8497//files/TAZ-TFG-2019-3529.pdf

López, R. (2006). Impensar la ciudad o en busca del pensamiento complejo. Un necesario recorrido epistemológico. En: Ramírez, V. y Blanca. R. (coord.). Formas territoriales. Visiones y perspectivas desde la teoría (pp. 15- 38). México: UAM-Porrúa.

Lynch, K. (1998). La imagen de la ciudad. Barcelona: Gustavo Gili. Mead, D. (20 I7). Una nueva perspectiva de la ciudad amurallada de Kowloon, el tugurio ciberpunk favorito de internet. Vice. Recuperado de https://www.vice.com/es/article/dpqz8k/unanueva-perspectiva-de-la-ciudad-amurallada-de-kowloon

Pallasmaa, J. (200 I). La arquitectura de la imagen: El espacio existencial en el cine. Helsinki: Rakenustieto Publishing.

Palomo, C. (2021). Impacto de la Realidad Mixta en la percepción del espacio arquitectónico. Tesis doctoral. Ciudad de México: Instituto Politécnico Nacional.Portella, I. (2019). La evolución de la arquitectura a través del cine. Blade Runner. Tesis de licenciatura. Escuela Técnica Superior de Arquitectura de Madrid. Recuperado de http://oa.upm. es/53872/I/TFG_Portella_Lezaun_Irene.pdf

Prokopljevic, J. (2020). La ciudad sobre resortes. Un experimento urbo-tecnológico de Anton Lavinsky, 1921. Veredes. Arquitectura y divulgación. Recuperado de https:// veredes.es/blog/la-ciudad-resortes-experimento-urbo-tecnologico-anton-lavinsky-1921 jelena-prokopljevicl

Real Academia de la Lengua Española [RAE] (2019). Percibir. Recuperado de https:// dle.rae.es/percibir?m=form

Sammon, P. (2017). The making of Blade Runner. Londres: Dey Street Books. Scott, R. (1982). Blade Runner [Película]. The ladd Company.

Spielberg, S. (2016). Ready Player One [Película]. Warner Bros Pictures.

Stephenson, N. (2000). Snow Crash.Traducción. Recuperado de https://mww.icesi.edu. co/blogs/identidadesavatar/files/2009/0I/neal_20stephenson_20-_20snow_20crash.pdf

Todo lo que sabemos sobre el Metaverso, el universo virtual a lo Ready Player One con el que sueña Epic Games (2020). Vida extra. Recuperado de https://mww.vidaextra. com/industria/todo-que-sabemos-metaverso-universo-virtual-a-ready-player-one-quesuena-epic-games

Venturi, R. (1972). Aprendiendo de Las Vegas. Barcelona: Gustavo Gili.Visualizando el futuro con Windows Mixed Reality (2016). Recuperado de https://www.youtube.com/ watch? $\mathrm{v}=2 \mathrm{MqGrF6} \mathrm{J} \mathrm{aOM}$

Zavala, L. (2003). Elementos del discurso cinematográfico. México: Universidad Autónoma Metropolitana.

Zevi, Bruno. (1969). L'aarchitettura. Cronache estoria. Milano: Etas Kompass. 